\title{
Barpress escape responses in the rat: A topographic analysis
}

\author{
R. V. RIAL, A. SAURA, M. P. TODÓ, and J. A. TUR \\ University of the Balearic Islands, Mallorca, Spain
}

\section{(Robert C. Bolles, Sponsor)}

By means of stroboscopic photography, barpress escape learning by rats was studied using two different schedules of negative reinforcement: fixed ratio 1 and variable ratio 2.5 . The results showed two different topographies of barpressing: with FR-1, the rat hit the bar with the foreleg in an intentional movement; however, when the schedule was changed, the response of the rat changed to a series of jumps on the bar. These results bear on the relation between the theory of species-specific defense reactions and escape behavior.

Bolles and McGillis (1968) doubted the operant nature of the barpress escape response in the rat because they found very short latencies between shock application and barpressing, which they took as evidence that the barpress was not an operant, but rather the result of a jump induced by the electric shock itself while the rat was freezing near the lever. According to them, the operant was the freezing in the neighborhood of the lever, and the barpress behavior was an artifact.

On the other hand, Bolles's (1970) theory of speciesspecific defense reactions (SSDR) proposes that there are three types of defense reactions in the rat: immobility (freezing), fleeing, and, under some circumstances, aggression or fighting. It seems difficult, however, to categorize the barpressing behavior into any of these three SSDRs.

Other authors have found, however, that rats press the lever in a different fashion from freezing (Daly \& McCroskery, 1973; Davis, Hirschorn, \& Hurwitz, 1973). In this paper, we describe a study of rats' responses in a barpress escape learning experiment in which a change in the schedule of reinforcement is made after a performance level has been attained. To show the effects of varying the contingency on the responses, we used stroboscopic photography to objectively and precisely measure the rats' behavior.

\section{METHOD}

\section{Subjects}

Five male Sprague-Dawley rats, 100 days old at the start of the experiment and weighing 200-250 g, were used. They were housed individually with food and water continually available except during experimental sessions.

\section{Apparatus}

The experimental chamber contained a lever operated by a $50-\mathrm{g}$ force and a grid floor through which continuous shock of 0-127 V ac (not

Requests for reprints should be addressed to: R. V. Rial, Department of Biology and Health Sciences, Faculty of Sciences, University of the Balearic Islands, 07071 Palma de Mallorca, Spain. scrambled) could be delivered. Electrical shock was supplied by a variable autotransformer, and the mean intensity was monitored by an oscilloscope. A digital clock coupled to the shock-delivery system and to the lever recorded reaction times.

Photographic records were taken with a 36-mm camera equipped with a stroboscopic flash unit delivering 70 flashes/second and a power drive that advanced the film at $400 \mathrm{~mm}$ uniform speed. The onset of a trial was marked by a neon lamp, powered by the ac mains, that flashed in synchrony with the alternating current. Since onset of the neon lamp was synchronized with shock onset, barpress reaction time could be taken directly from the photographic record.

\section{Procedure}

Escape barpressing was hand shaped. To prevent the animal's freezing, the experimenter varied the shock intensity depending on the animal's activity. Intensity was maximal (1.5 $\mathrm{mA}$, average) when the animal froze and minimal $(0.2 \mathrm{~mA})$ when activity occurred. Each escape barpress terminated grid shock for $30 \mathrm{sec}$ (fixed ratio 1 [FR-1] escape schedule), but between trials the lever was electrified to prevent intertrial barholding.

When escape barpressing was clearly established, the shock intensity was set at a fixed value of $0.7 \mathrm{~mA}$ and a set of 10-20 stroboscopic records of each animal was taken on each consecutive trial. Some examples of these pictures are shown in Figure 1. Next, the escape schedule was changed to a variable ratio (VR) of 2.5 (range: $2-3$ ) barpresses for each $30 \mathrm{sec}$ of shock-free time. The lever was again electrified between trials. Trials with the VR-2.5 schedule continued until barpressing was again stabilized and another set of stroboscopic pictures was taken of each animal.

From the photographic negatives, positive prints were obtained at a constant enlargement. Measurements of the foreleg, head, and bar were obtained and translated to distance-time graphs.

\section{RESULTS}

Escape reaction time from shock application to the effective barpress with FR-1 schedule varied from $7 \mathrm{sec}$ for Trials $1-20$ to $0.2 \mathrm{sec}$ for Trials $380-400$. When the schedule changed to VR-2.5, rats took 6-12 sec to escape from shock in Trials $0-40$, but this value fell to $2.5 \mathrm{sec}$ after 400 trials. It is interesting to note that after the schedule change, the latency to the first barpress remained in the 0.2 -sec region, but increased to $2.5 \mathrm{sec}$ after 100 trials with the new schedule, and then descended slowly to $0.7 \mathrm{sec}$ by Trials $380-400$. 

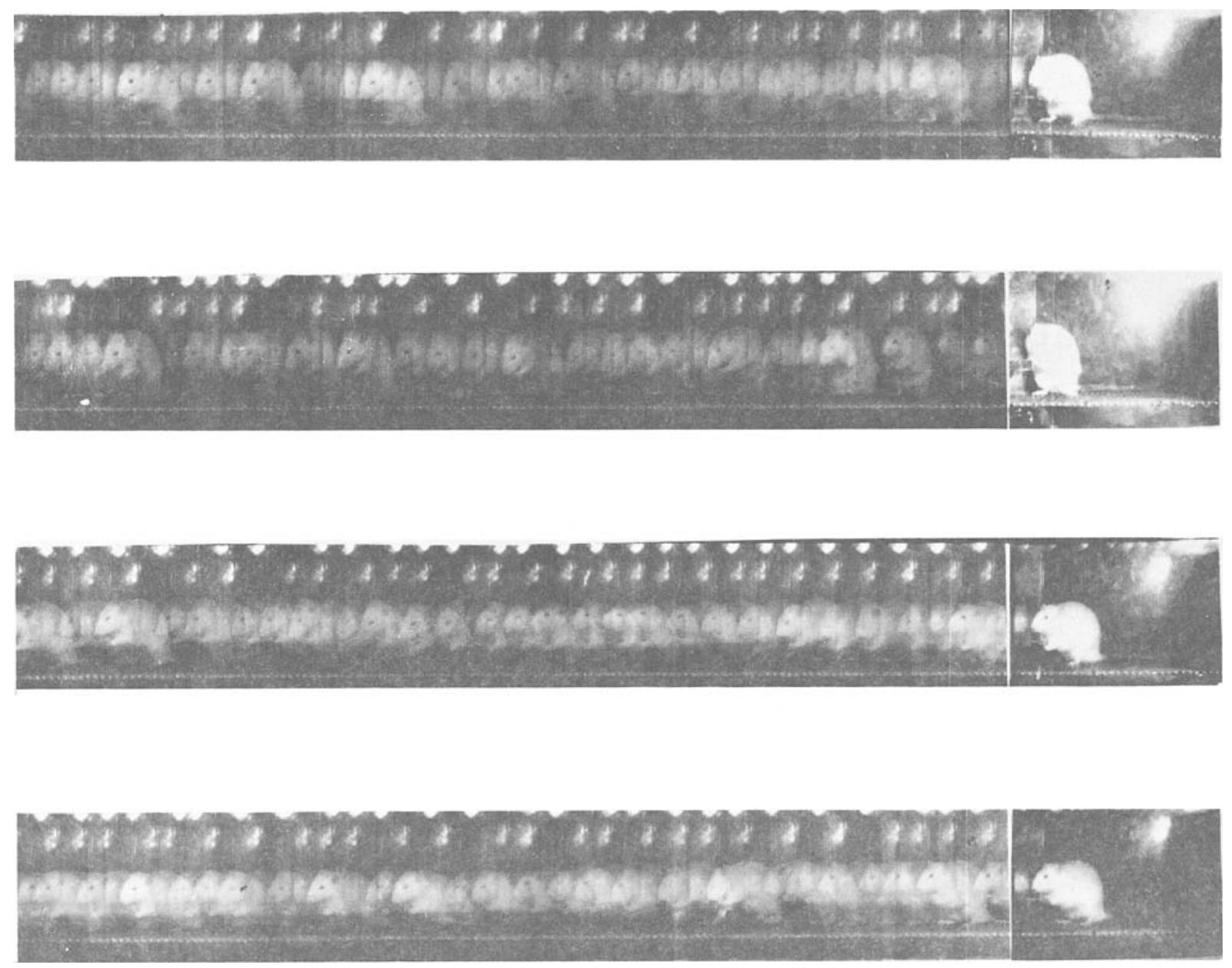

Figure 1. Stroboscopic films taken from four barpress escape trials during the FR-1 schedule. From each picture, measurements of the limb, head, and bar, relative to the cage floor, were taken to obtain the data presented in Figures 2 and 3 . The time sequence begins on the right.

The graphs showing a rat's head, foreleg, and lever movements in four trials under the FR-1 schedule are shown in Figure 2. In these graphs no absolute values of distances are given because these distances were obtained from the positive prints and the adjusted distances were not calculated for the graphs. Also, the photographs show the body and bar positions in the vertical plane, and horizontal differences in position cannot be measured. Additionally, and for clarity's sake, some lines have been translated to avoid intersections (e.g., when the leg is applied to the bar, the trajectory of both leg and bar should be only one line; instead, two different but parallel lines are represented). In short, these graphs show vertical movements of head, foreleg, and lever, relative to the cage floor, plotted against time. Note the following: (1) The bar was always pressed with the foreleg, and its movement was always independent of the rest of the body; on occasion it even had a divergent trajectory. (2) The trajectory of the barpressing leg was always diphasic: first, there was a backward movement and then the limb turned to the lever until bar depression was completed. Thus the graphs show a characteristic S-shaped configuration. (3) Total response time was on average $0.2 \mathrm{sec}$, but the leg that pressed the bar began to move $30-50 \mathrm{msec}$ after shock onset.

Figure 3 shows the results of four trials obtained under the VR-2.5 escape schedule. Note the following: (1) The trajectory of the barpressing limb was always parallel to the trajectory of the head. (2) The barpress was always made with the hind leg and performed by direct approach of the leg to the lever, without a previous phase of limb withdrawal.

\section{DISCUSSION}

The main apparent result of this study is the dramatic effect of the change from FR-1 to VR-2.5 schedule on the rat's barpress escape behavior. In fact, this change produced an extinction of the previously acquired barpressing behavior and the acquisition of a new and differ- 

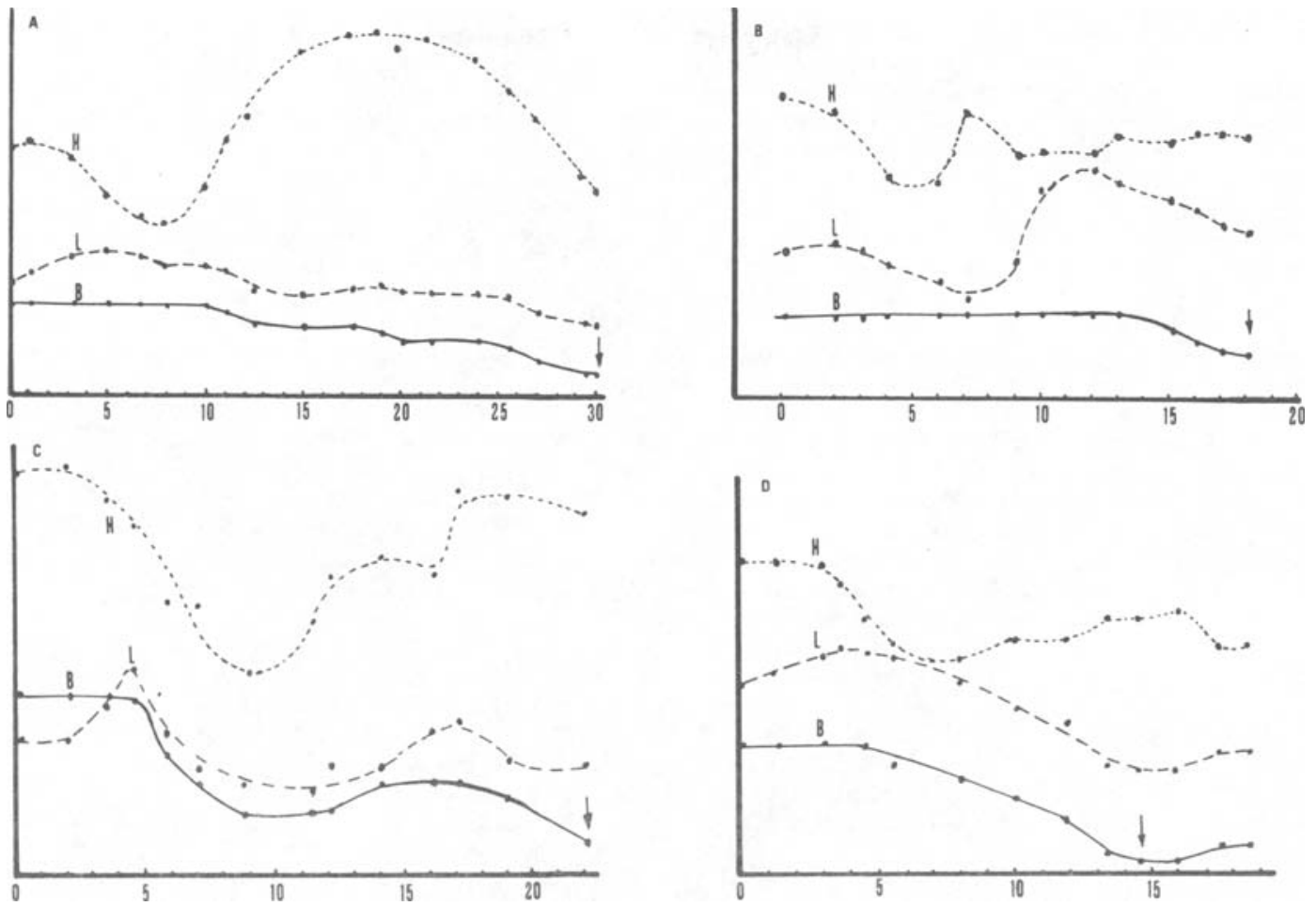

Figure 2. Topographic analysis of four barpressing escape trials under the FR-1 schedule. Each line shows the trajectory of head (H), limb (L), and bar (B). Arrows mark the ends of the shocks. Vertical axes show distances from body points to the cage floor in horizontal axis time $(.01 \mathrm{sec})$.
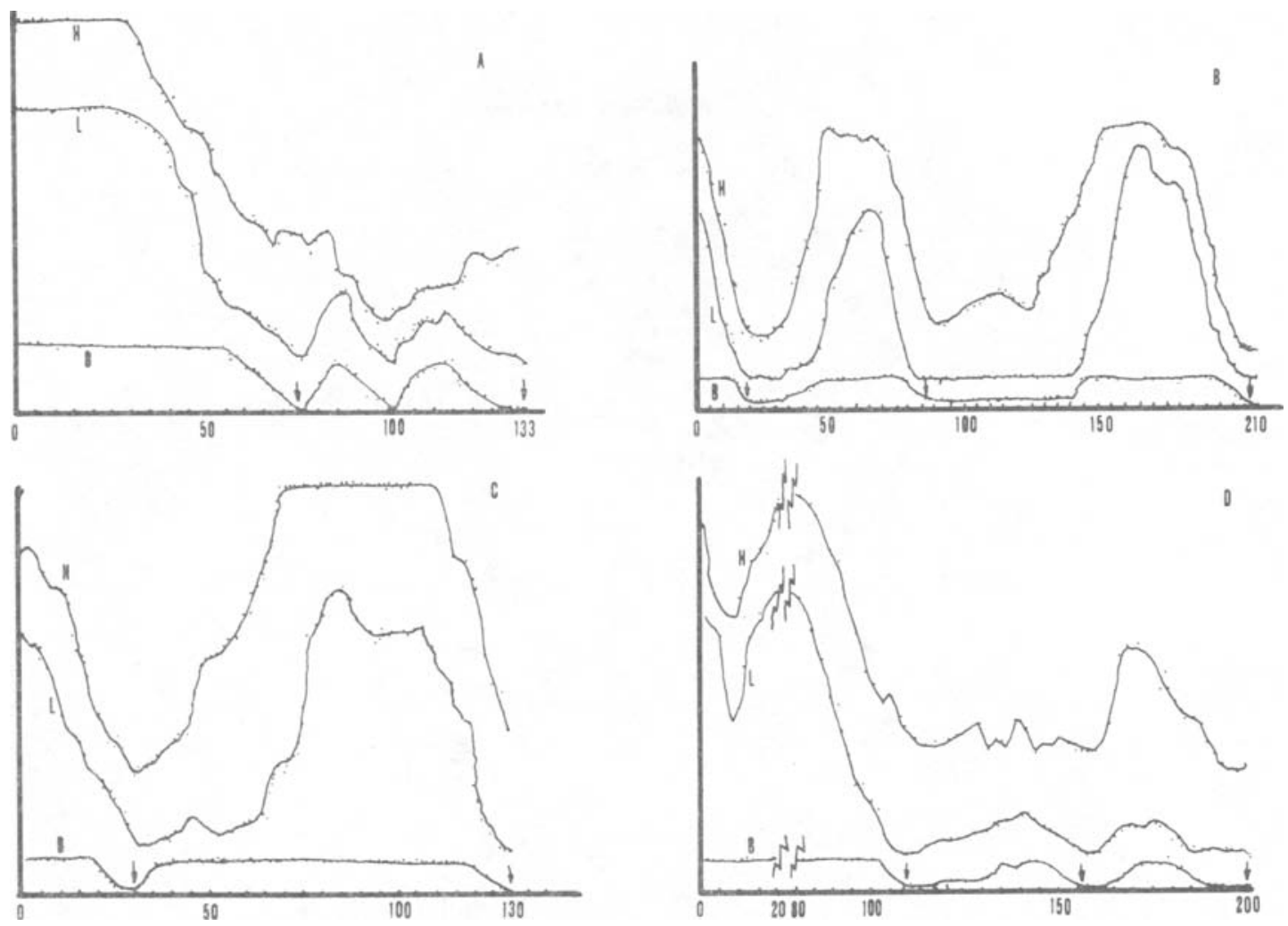

Figure 3. Topographic analysis of four barpressing escape trials under the VR-2.5 schedule. Each line shows the trajectory of head (H), limb (L), and bar (B). Arrows mark the ends of effective barpressing and shock offset. Vertical axes show distances from body points to the cage floor in horizontal axis time (.01 sec). 
ent behavior. The existence of two different strategies of barpressing corresponding to the two schedules is demonstrated by the fact that there are differences in morphology, timing, and latencies: the increased latencies during the early trials of the VR-2.5 schedule indicate that when the subjects discovered that the former successful strategy was no longer practical (i.e., when the schedule was changed), they switched to another strategy and needed some time and trials to perfect the new one. This data indicates that the barpressing obtained with the FR-1 schedule was clearly an operant, since it was changed by its consequences.

The differences between the results reported here and those obtained by Bolles and McGillis (1968) are probably due to the very different experimental designs. In this study, responses were shaped intentionally to provoke activity. In Bolles and McGillis's study, barpressing was recorded by electromyograph (EMG) and rendered, with good verisimilitude, an unintended shaping to immobility, because an isometric muscular contraction was enough to offset the shock. At the same time, the electromyographical method produced very short latencies: Bolles and McGillis reported that the onset of EMG activity occurred within 30-40 msec, which is very close to the speed obtained here for the start of the response, but here the whole action took three or four times this long to complete. It is evident that if the EMG would have better determined the shock end, this ending would have occurred much earlier.

Based on this information, it seems that the barpressing may or may not be an operant, depending very much on the experimental design used. From the results of this study, it seems quite clear that barpressing with the VR-2.5 schedule is not an operant, but is instead the result of a series of jumps in the neighborhood of the lever. In this case, the operant would be the activity in this neighborhood, not the barpressing itself.
Having concluded this, we are left with the question of how to reconcile the results with the SSDR theory. We can only make some suggestions: Bolles and McGillis (1968) described the rat's barpress escape response as characteristic of freezing; perhaps the responses reported here for the FR-1 schedule can be described as punches or kicks to the lever, which have been reported in the rat as aggressive behaviors (EiblEibesfeldt, 1957). This possibility has been suggested (Bolles, 1971), especially when the lever is electrified. Finally, the jumps during the VR-2.5 schedule seem characteristic of fleeing behavior. Because experimental design seems to be the paramount factor in determining which defense reaction is shown by the rat, further research is needed to explain barpress escape responses in terms of the SSDR theory.

\section{REFERENCES}

Bolles, R. C. (1970). Species-specific defense reactions and avoidance learning. Psychology Review, 77, 32-48.

BoLLEs, R. C. (1971). Species-specific defensive reactions. In R. Brush (Ed.), Aversive conditioning and learning. New York: Academic Press. Bolles, R. C., \& McGillis, D. B. (1968). The non-operant nature of the bar-press escape response. Psychonomic Science, 11, 261-262.

Daly, H. B., . \& McCroskerY, J. H. (1973). Acquisition of a bar-press escape response to escape frustrative nonreward and reduced reward. Journal of Experimental Psychology, 98, 109-112.

Davis, H., Hirschorn, P., \& Hurwitz, H. (1973). Lever holding behavior during a leverlift shock escape procedure. Animal Learning \& Behavior, 1, 215-218.

EIBL-EIBESFELDT, I. (1957). Rattus norvegicus. Kampf I (Erfahrener Mannchen). Encycl. Cinem. E 131 (Inst. Wiss. Film.). 